\title{
Polyunsaturated fatty acids synergize with lipid droplet binding thalidomide analogs to induce oxidative stress in cancer cells
}

\author{
László G Puskás*1,2,3, Liliána Z Fehér1, Csaba Vizler4, Ferhan Ayaydin5, Erzsébet Rásó6, Eszter Molnár2,3, István Magyary7,

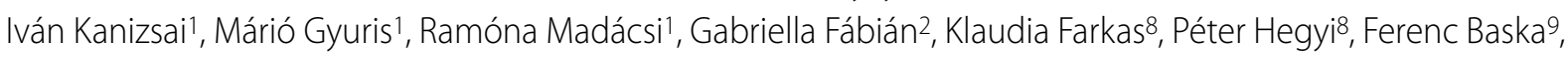 \\ Béla Ózsvári1 and Klára Kitajka1,3
}

\begin{abstract}
Background: Cytoplasmic lipid-droplets are common inclusions of eukaryotic cells. Lipid-droplet binding thalidomide analogs (2,6-dialkylphenyl-4/5-amino-substituted-5,6,7-trifluorophthalimides) with potent anticancer activities were synthesized.

Results: Cytotoxicity was detected in different cell lines including melanoma, leukemia, hepatocellular carcinoma, glioblastoma at micromolar concentrations. The synthesized analogs are non-toxic to adult animals up to $1 \mathrm{~g} / \mathrm{kg}$ but are teratogenic to zebrafish embryos at micromolar concentrations with defects in the developing muscle. Treatment of tumor cells resulted in calcium release from the endoplasmic reticulum (ER), induction of reactive oxygen species (ROS), ER stress and cell death. Antioxidants could partially, while an intracellular calcium chelator almost completely diminish ROS production. Exogenous docosahexaenoic acid or eicosapentaenoic acid induced calcium release and ROS generation, and synergized with the analogs in vitro, while oleic acid had no such an effect. Gene expression analysis confirmed the induction of ER stress-mediated apoptosis pathway components, such as GADD153, ATF3, Luman/CREB3 and the ER-associated degradation-related HERPUD1 genes. Tumor suppressors, P53, LATS2 and ING3 were also up-regulated in various cell lines after drug treatment. Amino-phthalimides down-regulated the expression of CCL2, which is implicated in tumor metastasis and angiogenesis.
\end{abstract}

Conclusions: Because of the anticancer, anti-angiogenic action and the wide range of applicability of the immunomodulatory drugs, including thalidomide analogs, lipid droplet-binding members of this family could represent a new class of agents by affecting ER-membrane integrity and perturbations of ER homeostasis.

\section{Background}

Cytoplasmic lipid-droplets (LDs) are common inclusions of eukaryotic cells. Little is known about the composition or physiological role of LDs, however growing number of evidences imply that LDs are not solely static inclusions for storage of excess lipid, but they are dynamic and functionally active [1-4]. Although LD biogenesis is not well understood, it is assumed that the LDs form within the two leaflets of the ER membrane to function as lipid storage sites [5]. LDs are active inclusions with essential roles in membrane trafficking, cell signaling and distributing

\footnotetext{
*Correspondence: laszlo@avidinbiotech.com

1 Avidin Biotechnology, Közép fasor 52., Szeged, H-6726, Hungary Full list of author information is available at the end of the article
}

specific lipids and proteins [6,7]. LDs are also sites for cytokine storage in inflammatory leukocytes, suggesting that LDs function as inducible intracellular platforms for spatial segregation and organization of signaling leading to inflammatory mediator secretion during inflammation [8]. Under hypoxic conditions or when free fatty acid overload occurs (exogenously from the serum or due to intracellular alterations e.g. when beta-oxidation is blocked) the number of LDs increases [9]. It was shown that LD accumulation occurs in vivo at prenecrotic cancer tissues [10] and border zones of experimental myocardial infarcts [11], therefore LDs can be in vivo markers of cancer and ischemic insults [12]. When the amount, distribution and the rate of formation of LDs are altered 
by small molecules, membrane transport and lipid homeostasis could be impaired in cancer cells. Thus, tumor cells are much more dependent upon fatty acid removal than normal cells, where beta-oxidation is not affected by oxygen depletion. Imbalance in lipid homeostasis can finally lead to membrane disruption and activation of lipoapoptosis [13]. As LDs are formed in the ER we hypothesized that specific LD-binding drugs could interfere with LD homeostasis and ER-membrane integrity and could trigger apoptosis through ER stress.

We synthesized novel LD-binding thalidomide analogs (amino-substituted-trifluoro-phthalimides), with strong inherent blue fluorescence, which localize specifically to LDs and at higher concentrations to ER. They possess potent anticancer activities in vitro in a variety of cell lines and they, like non-fluorescent immunomodulatory drugs (IMiDs) and thalidomide analogs such as Revlimid (lenalidomide), Actimid and CPS49 [14,15], induce reactive oxygen species (ROS) originating in the ER [16].

Thalidomide is best known as a major teratogen that caused birth defects (stunted limb growth) in up to 12,000 children in the $1960 \mathrm{~s}$. Despite its tragic initial experience, thalidomide has become the subject of major interest because of its wide range of biological activities and newly demonstrated clinical value in infectious disease and cancer $[17,18]$. Thalidomide and their analogs are currently being used experimentally to treat various cancers and inflammatory diseases (for review see $[14,17,18])$. Because the use of thalidomide is limited by toxicity and limited efficacy, novel and more potent derivatives are under development [18-21].

Here, we studied the interacting protein targets of amino-substituted-trifluoro-phthalimides and their effects on calcium-release, ROS production, ER-stress and gene expression changes in different treated cancer cells. We also examined whether different fatty acids could influence the effects of our new compounds. Our results might open novel therapeutic strategies by using LD-binding molecules and also emphasize the importance of nutritional lipids on tumor response to anti-neoplastic agents.

\section{Materials and methods Chemicals}

2,6-diisopropylphenyl-4/5-amino-substituted-4/5,6,7-trifluorophthalimides (AC-177: 4-cyclopentyl-; AC-202: 5ethyl-; AC-1041: 4-morpholine-) were synthesized from 2,6-diisopropylphenyl-4-5,6,7-tetrafluorophthalimide

[21] and pentylamine, ethylamine or morpholine (Sigma, USA) in chloroform at reflux temperature for $6 \mathrm{~h}$. The 4(e.g. AC-177 or AC-1041) and 5- (e.g. AC-202) isomers were separated in silica column chromatography by using hexane:chloroform (1:1) eluent. The purity of the compounds was assessed by HPLC. The structure of the com- pounds was confirmed by NMR or X-ray diffraction (data not shown). Other IMiDs (CPS49: 4,5,6,7-tetrafluoro-2(2,4-difluorophenyl)isoindol-1,3-dione; TFFI: 4,5,6,7-tetrafluoro-2-(4-fluoro-phenyl)-isoindole-1,3-dione; CPS48: 5-(tetrafluorophthalimido)-pyrimidine-2,4 $(1 \quad \mathrm{H}, \quad 3 \mathrm{H})$ dione were synthesized according to US 20040077685A1 patent. Lenalidomide (cc5013) was purchased from Hallochem (Chongqing, China), thalidomide and other chemicals from Sigma (St. Louis, MO, USA).

\section{Intracellular localization}

HepG2 and HT168 cells were grown on cover-slips, washed in phosphate-buffered saline (PBS), and fixed for $10 \mathrm{~min}$ at room temperature with $4 \% \mathrm{p}$-formaldehyde in PBS supplemented with $5 \mathrm{mM}$ each of $\mathrm{MgCl}_{2}$ and EGTA. After washing with PME, LDs were first stained with oil red $\mathrm{O}$ for $10 \mathrm{~min}$, than incubated with $10 \mu \mathrm{M} \mathrm{AC} \mathrm{com-}$ pounds in PME for 5 min and mounted in FluoromountG mounting solution (Southern Biotechnology Associates, Birmingham, AL). HT168 cells were cultured in glass bottom culture dishes (MatTek Corporation, Ashland, MA). ER was labeled with BODIPY-FL-glibenclamid according to the ER-Tracker Green (Invitrogen, Carlsbad, CA) manufacturer's protocol in live cells. After staining we replaced the solution with fresh Hank's Balanced Salt Solution with calcium and magnesium containing $5 \mu \mathrm{M} \mathrm{AC}-202$ or AC-1041 and after $5 \mathrm{~min}$ the cells were visualized using fluorescence microscope.

Fluorescence microscopy was performed using a confocal microscope (Olympus Fluoview FV1000 Confocal Laser Scanning Microscope) equipped with 20× (N.A 0.75 ) and $40 \times$ oil (N.A 1.3) objectives. We applied a 543 $\mathrm{nm}$ laser with Alexa Fluor 546 configuration for detection of oil red O staining of oil bodies and $405 \mathrm{~nm}$ laser with DAPI configuration for detection of AC compounds.

In vivo staining with AC-202 was performed on SCID mouse after 28 days intra-spleen inoculation of $10^{6}$ HT168 cells. $2 \mathrm{~h}$ after single oral administration of 200 $\mathrm{mg} / \mathrm{kg}$ AC-202, mice were sacrificed and livers were frozen and sectioned for confocal microscopy.

\section{Cell culture studies}

HepG2 (hepatocarcinoma) and MCF7 (breast adenocarcinoma), U87 (glioblastoma), HT168 (melanoma), K562, HL60 (myeloid leukemia), U266 (multiple myeloma) cells were obtained from the ATCC collection and maintained in suggested medium in a humidified atmosphere of $95 \%$ air and $5 \% \mathrm{CO}_{2}$. For cytotoxicity assays, 10.000 cells were seeded into one well of 96-well cell culture plates. Effects of the analogs were recorded 24-72 $\mathrm{h}$ after treatment. MTS (3-(4,5-dimethylthiazol-2-yl)-5-(3-carboxymethoxy-phenyl)-2-(4-sulfophenyl)-2H-tetrazo-

lium) assay was applied to drug treated and control $(0.2 \%$ DMSO) cells at different concentrations with CellTiter 
$96^{\circ}$ AQueous Assay (Promega, Madison, WI) according to the manufacturer's protocol.

For gene expression analysis cell lines (K562, HL60, U266, HT168, U87, HepG2 and MCF7) (seeded at a density of $5 \times 10^{4}$ cells $/ \mathrm{cm}^{2}$ into $100 \mathrm{~mm}$ cell culture dishes) were treated with different drugs at different concentrations (thalidomide: $100 \mu \mathrm{M}$, cc5012: $20 \mu \mathrm{M}$, CPS48: 20 $\mu \mathrm{M}$, TFFi: $10 \mu \mathrm{M}$, CPS49: $10 \mu \mathrm{M}$ and AC-1041: $10 \mu \mathrm{M}$ ) for $4 \mathrm{~h}$. Quadruplicate samples for each compound and their respective controls were collected.

\section{Intracellular calcium ion determination}

Cultured K562 cells were attached, using Cell-Tak, to a coverslip (ø $24 \mathrm{~mm}$ ) forming the base of a perfusion chamber mounted on an Olympus microscope (Olympus, Budapest, Hungary). The K562 cells were bathed in standard Hepes solution at $37^{\circ} \mathrm{C}$ and loaded with the $\mathrm{Ca}^{2+}$-sensitive fluorescent dye FURA 2-AM (4-5 $\left.\mu \mathrm{mol} / \mathrm{L}\right)$ for $30 \mathrm{~min}$. After loading, the cells were continuously perfused with solutions at a rate of $4-5 \mathrm{~mL} / \mathrm{min}$. Changes in intracellular $\mathrm{Ca}^{2+}$ concentration $\left(\left[\mathrm{Ca}^{2+}\right]_{\mathrm{i}}\right)$ were measured using a CellR imaging system (Olympus). Each cell was excited with light at wavelengths of $340 \mathrm{~nm}$ and $380 \mathrm{~nm}$, and the 380/340 fluorescence emission ratio was measured at $510 \mathrm{~nm}$. One $\left[\mathrm{Ca}^{2+}\right]_{\mathrm{i}}$ measurement was obtained per second. The standard Hepes-buffered solution contained $130 \mathrm{mM} \mathrm{NaCl}, 5 \mathrm{mM} \mathrm{KCl}, 1 \mathrm{mM} \mathrm{CaCl}, 1 \mathrm{mM}$ $\mathrm{MgCl}_{2}, 10 \mathrm{mM}$ D-glucose and $10 \mathrm{mM} \mathrm{Na-Hepes.} \mathrm{Cells}$ were loaded with AC-1041 for $2 \mathrm{~min}$.

\section{ROS determinations}

ROS generation was determined by the increase in DCFDA (2',7'-dichlorodihydrofluorescein diacetate, Sigma) fluorescence after drug stimulation. HT168 cells were washed, resuspended in $1 \%$ bovine serum albumin in Hanks buffered saline solution (BSA-HBSS) at $10^{6}$ cells $/ \mathrm{mL}$ and maintained at $37^{\circ} \mathrm{C}$ for analysis. Cells were treated with the indicated drugs (AC-177, CPS49) and with or without different antioxidants (rotenone: $0.1 \mu \mathrm{M}$; gluthatione (GSH): $0.4 \mathrm{mM} ; \mathrm{N}$-acetyl cysteine (NAC): 0.4 $\mathrm{mM}$; tiron: $0.5 \mathrm{mM}$; epigallocatechin (EPG): $0.1 \mathrm{mM}$; buthylsulfoxide (BSO): $0.1 \mathrm{mM}$; catalase: $100 \mathrm{U}$; vitamin C: $50 \mu \mathrm{M})$, fatty acid (EPA: $50 \mu \mathrm{M})$ and BAPTA-AM (50 $\mu \mathrm{M})$. DCFDA was added $60 \mathrm{~min}$ prior to harvest, at $2 \mu \mathrm{M}$ final concentration. All the other parameters and calculations were done as described before [16].

\section{Toxicity and teratogenic analysis}

Acute toxicology studies were performed on twomonths-old male $\mathrm{CD} / 1$ mice and Wistar female rats that were kept in a conventional animal house and received conventional food pellets and tap water ad libitum throughout the experiments. One dose of AC-202 or AC1041 at $800 \mathrm{mg} / \mathrm{kg}$ or $1.2 \mathrm{~g} / \mathrm{kg}$ dose was orally given to 10 animals in $0.5 \%$ methylhydroxyl-cellulose suspension by gavage $(0.45 \mathrm{ml}$ for mice and $2 \mathrm{ml}$ for rats). Additionally, one dose of $2 \mathrm{~g} / \mathrm{kg}$ of AC-202 was orally given to 10 rats. Toxic effects were recorded for 2 weeks. All animal experiments were performed respecting institutional animal welfare guidelines.

Teratogenic analysis was performed on zebrafish embryos [22]. AC-202, AC-1041 and thalidomide were dissolved in DMSO at final concentration of $1 \mathrm{mM}$. One in 1000 and $1 / 200$ dilutions were applied into the water. Malformations and death were recorded at 24, 48 and 72 hpf (hours post fertilization).

\section{Gene expression analysis}

Total RNA was purified from drug treated and control (0.2\% DMSO) cells at various concentrations with AccuPrep $^{\mathrm{m}}$ RNA purification kit (Bioneer, Daeleon, Korea) according to the manufacturers' protocol, except that DNase I treatment was incorporated.

For DNA-microarray analysis human microarrays of 8plex format from Agilent Technologies (Palo Alto, CA, USA) with 14,833 probes were used. $1 \mu \mathrm{g}$ of total RNA from AC-1041-treated and control K562 cells were amplified with the AminoAllyl MessageAmp ${ }^{\text {Tn }}$ II aRNA Amplification Kit (Ambion, Austin, Texas), and labeled with either $\mathrm{Cy} 5$ or $\mathrm{Cy} 3$ dyes according to the manufacturer's instructions (Ambion). Each array was scanned at $543 \mathrm{~nm}$ (for Cy3 labeling) or at $633 \mathrm{~nm}$ (for Cy5 labeling) in Agilent Scanner using the built-in XDR (Extended Dynamic Range) function with $5 \mu \mathrm{m}$ resolution. Output image analysis and feature extraction was done using Feature Extraction software of Agilent. DNA-microarray study was done in quadruplicates and with dye-swap protocol. The results were deposited at GEO (Gene Expression Omnibus) database with an accession number: GSE14945.

For quantitative real-time PCR (QRT-PCR) total RNA $(2 \mu \mathrm{g})$ was converted into cDNA with the High-Capacity cDNA Archive Kit (Applied Biosystems, Foster City, CA) and without purification the mixture was applied to QRT-PCR analysis. QRT-PCR was performed on a RotorGene 3000 instrument (Corbett Research, Sydney, Australia) with gene-specific primers http://www.brc.hu/ pub/LHD/LHDPrimers.xls and SybrGreen protocol [23]. Curves were analyzed by using dynamic tube and slope correction methods with ignoring data from cycles close to baseline. Relative expression ratios were normalized to the geometric mean of two housekeeping genes, ubiquitin and hypoxanthin phosphoribosyltransferase.

\section{Results}

\section{Novel thalidomide analogs}

Novel thalidomide analogs, 2,6-diisopropylphenyl-4/5amino-substituted-4/5,6,7-trifluorophthalimides (AC- 
177: 4-pentyl-; AC-202: 5-ethyl-; AC-1041: 4-morpholine-) were synthesized from 2,6-diisopropylphenyl-45,6,7-tetrafluorophthalimide [24] (see structures in Fig. $1)$. Several primary and secondary amine compounds including heterocyclic structures were chemically reacted and novel thalidomide derivatives were prepared and characterized (unpublished results). All possessed a strong blue fluorescence (e.g.: AC-202: $\Lambda_{\mathrm{ex}}: 377 \mathrm{~nm}, \Lambda_{\mathrm{em}}$ : $481 \mathrm{~nm})$, that made cell/animal analyses more convenient.

\section{Intracellular localization}

Fluorescence confocal microscopic study was undertaken to determine the subcellular localization of the new thalidomide analogs in human cells. AC compounds exhibited specific staining of LDs at $5 \mu \mathrm{M}$ concentration assessed by complete co-localization with oil red $\mathrm{O}$, an LD-specific dye in HT168 human melanoma cells (for AC-202 see Fig. 2a-c). When higher concentrations and higher laser power were applied, AC-202 also showed ER localization (Fig. 2d-f). Complete LD co-localization for all AC compounds listed in the Materials and Methods section were reproducible on other cell lines (MCF7, HepG2, A549, K562, HL60, U87, U266), as well (data not shown).

In vivo staining of pre-necrotic, necrotic tumor tissues (human HT168 melanoma cells) in SCID mouse liver could be seen after single oral administration of $200 \mathrm{mg} /$ kg AC-202 (Fig. 2g-i). Lipid droplets were accumulated in tumor tissues and were stained by the inherent fluorescence of the analog AC-202, while normal liver tissues lack LDs and therefore, had much less fluorescent signals.

\section{In vitro effects on cancer cells}

Amino-trifluoro-phthalimides exerted potent anticancer activities in vitro. Cytotoxicity was evident after 4-16 h exposure depending on the cell type (data not shown). In human erythroleukemia cells (K562), which showed significant resistance against several thalidomide analogs

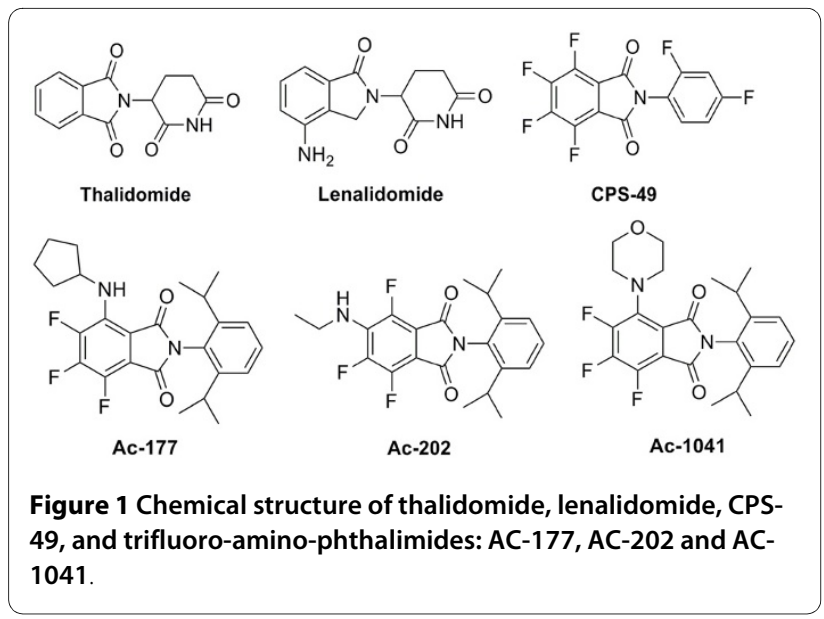

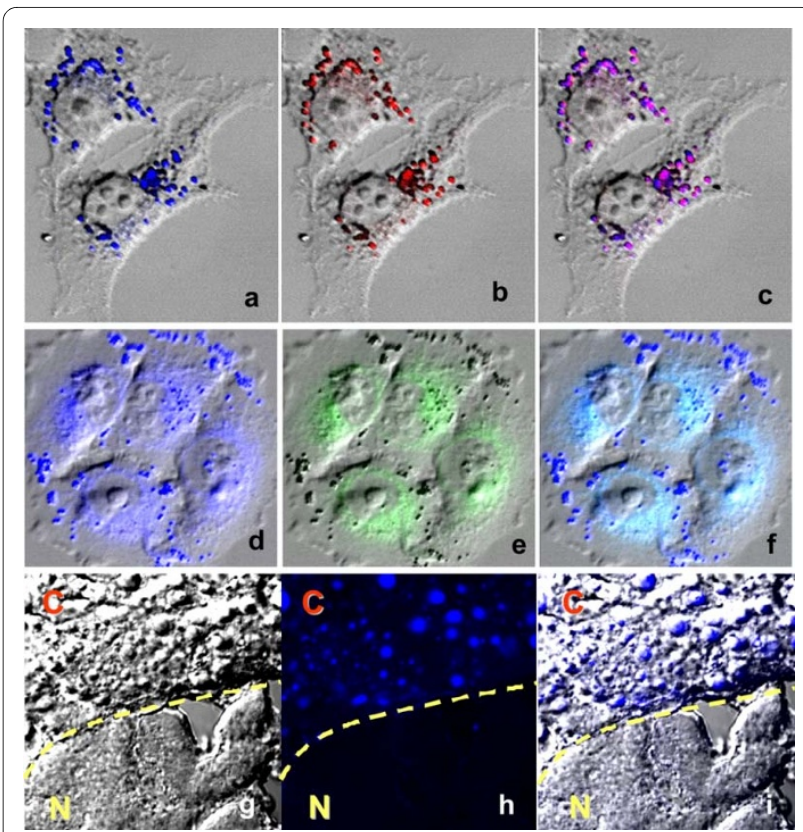

Figure 2 Intracellular localization of AC-202. HT168 human melanoma cells were double-stained with the blue fluorescent AC-202 (a. 5 $\mu \mathrm{M} ; \mathrm{d} .20 \mu \mathrm{M}$ ), lipid droplet-specific dye (oil red O) (b), and endoplasmic reticulum-specific dye (ER-Tracker $\left.{ }^{\mathrm{TM}} \mathrm{Green}\right)$ (e). Purple color derives from co-localization of oil red O and AC-202 (c). Cyan color derives from co-localization of ER-Tracker ${ }^{\mathrm{TM}}$ and AC-202 (f). Pictures $d$-f were recorded with higher laser power. In vivo staining of lipid droplets in prenecrotic cancer tissues (HT168 xenograft) in liver of SCID mouse by AC-202 (g-i). "C" denotes for cancer tissue, "N" for normal. Cancer and normal cells are separated by a dashed line.

[15], amino-trifluoro-phthalimides were effective below $10 \mu \mathrm{M}$ concentration (for AC-1041 see Fig. 3).

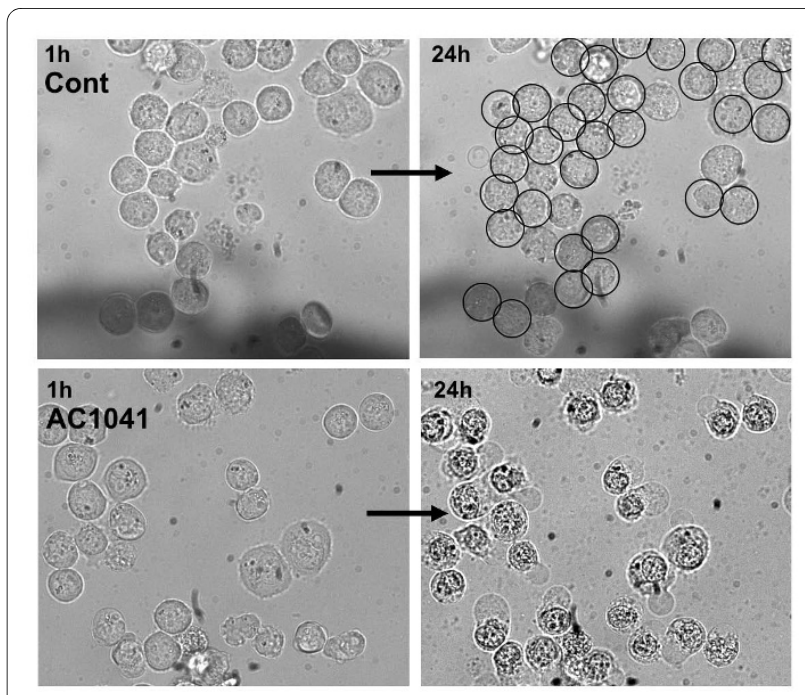

Figure 3 Cytotoxic activity of $10 \mu \mathrm{M} \mathrm{AC}-1041$ on human erythroleukemia cells. Pictures were recorded from the same area after $1 \mathrm{~h}$ and $24 \mathrm{~h}$ treatment. Cont: control cell lines treated with vehicle $(0.1 \%$ DMSO). Cell divisions between $4 \mathrm{~h}-24 \mathrm{~h}$ are labeled with circles. 
Cytotoxicity could be observed in all cell lines analyzed: in leukemia (K562, HL60), myeloma (U266), glioblastoma (U87), melanoma (HT168), breast cancer (MCF7) and hepatocellular carcinoma (HepG2). The most effective compound was $\mathrm{AC}-1041$ with $\mathrm{IC}_{50}$ values of 5-15 $\mu \mathrm{M}$. The most sensitive cell lines were the leukemia cells ( 5 $\mu \mathrm{M})$, while melanoma, hepatocellular carcinoma and glioblastoma cell lines were the most resistant $(15 \mu \mathrm{M})$.

\section{Elevation of intracellular calcium ion and ROS}

In human erythroleukemia cells (K562) LD-binding amino-trifluoro-phthalimides induced intracellular calcium ion release from the ER (see Fig. 4 for induction by AC-1041 at $10 \mu \mathrm{M}$ concentration) as detected by measurement of the $\mathrm{Ca}^{2+}$-sensitive fluorescent dye FURA 2AM for 30 min after drug administration. AC-1041 evoked a large initial peak in $\left[\mathrm{Ca}^{2+}\right]_{\mathrm{i}}$ followed by a sustained plateau in $25 \%$ of the cells, however, in $14 \%$ of the cells AC-1041 evoked repetitive $\left[\mathrm{Ca}^{2+}\right]_{\mathrm{i}}$ transients. $61 \%$ of the cells did not (or very slightly) respond.

To investigate whether amino-trifluoro-phthalimides exert a pro-oxidative effect, the presence of ROS in cancer cells was measured after exposure of the cells to the analogs. AC-177 and other analogs generated significant levels of ROS in HT168 cells, while control compounds cc5013, thalidomide and CPS49 showed only minimal elevation compared with that of untreated HT168 cells (for CPS49 and AC-177 ROS levels, see Fig. 5A). The effects of different antioxidants (rotenone, GSH, NAC, tiron, EPG, BSO, catalase and vitamin C) and polyunsaturated fatty acid EPA were also recorded on ROS production (Fig. 5A). Among the antioxidants only NAC and tiron could diminish ROS production. Interestingly, vitamin C and EPA raised the AC-177-induced ROS levels. Moreover, the addition of different polyunsaturated fatty acids (PUFAs) (EPA or DHA) in combination with AC177 resulted in synergistic effects on ROS production

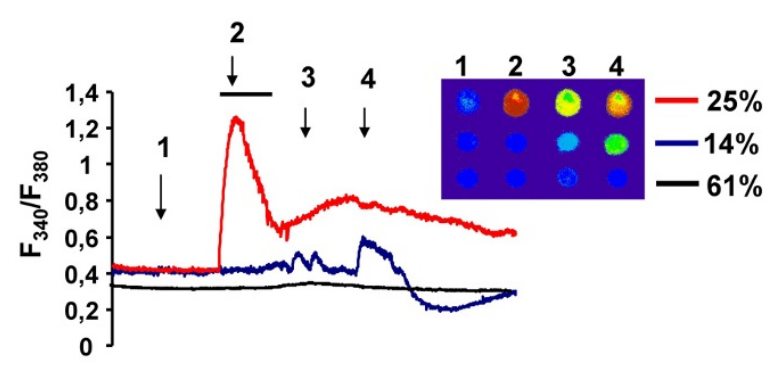

Figure 4 Representative experimental traces showing the different effects of $A C-1041$ on $\left[\mathrm{Ca}^{2+}\right]_{i}$ in perfused $\mathrm{K} 562$ cells. Shown are the typical patterns of $\left[\mathrm{Ca}^{2+}\right]_{i}$ changes in the cells perfused with AC1041. Increase in $\left[\mathrm{Ca}^{2+}\right]_{\mathrm{i}}$ is denoted by a change from a "cold" color (blue) to a "warmer" color (yellow to red). Pictures 1-4 were taken at the times indicated in the graph.

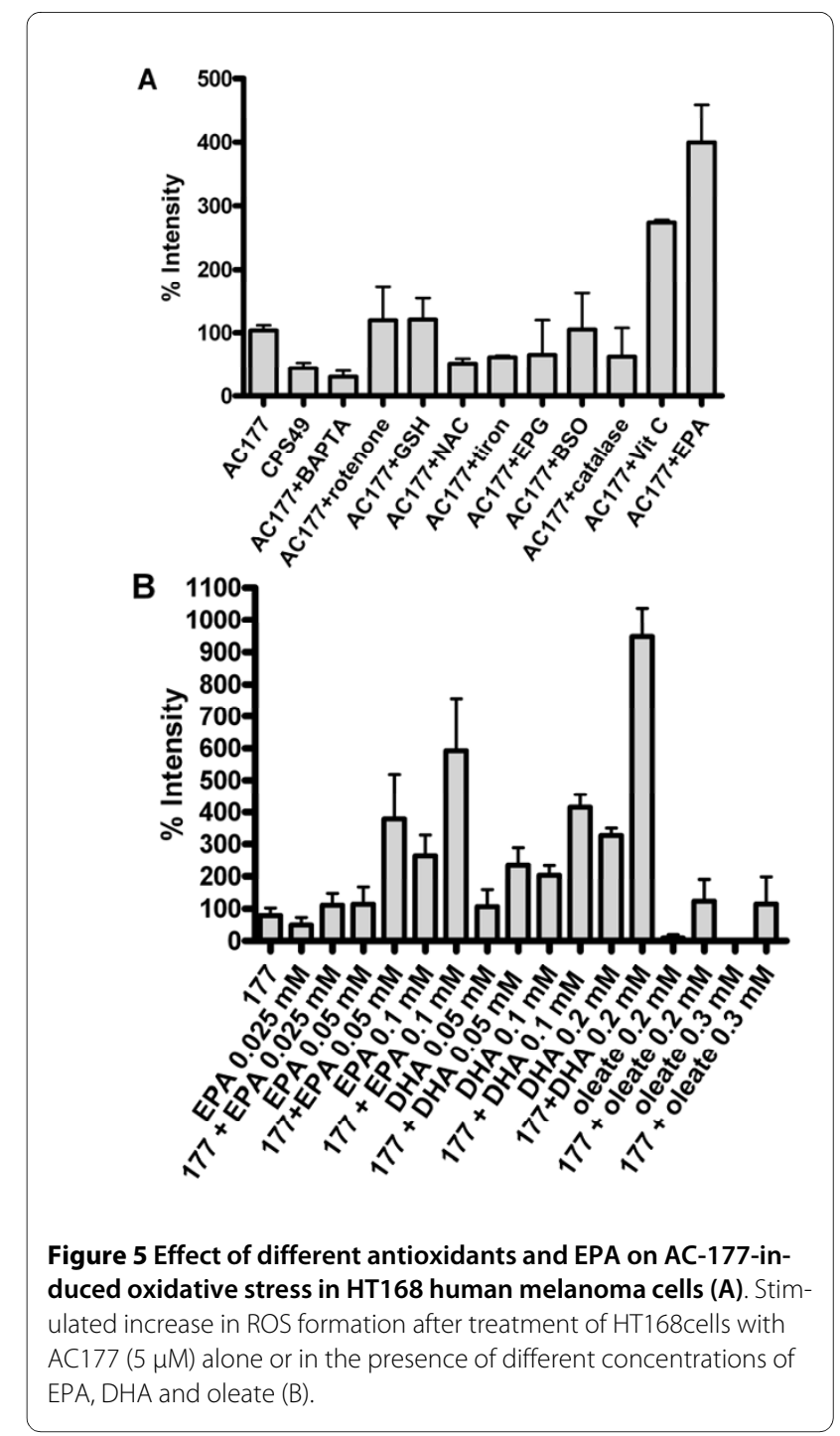

(Fig. 5B). When oleic acid was used no such an effect could be detected. The synergistic effect of EPA or DHA was concentration dependent. This could be seen with the LD-binding amino-trifluoro-phthalimides treatment, but the effect was lacking or was more moderate for other thalidomide analogs (for CPS49 see Fig. 5A).

To reveal the correlation of induction of intracellular calcium ion and ROS production of the analogs we studied the effects of cell-permeable calcium chelating agent, BAPTA-AM together with AC-177 and with PUFAs. We found that BAPTA-AM almost completely abolished ROS formation of AC-177 alone or with the PUFAs used (Fig 5A).

\section{Toxicity and teratogenicity}

Acute toxicology studies were performed on $\mathrm{CD} / 1$ mice and Wistar rats. AC-202 or AC-1041 was administered orally. There were no toxic effects up-to very high concentrations (LD50: $1 \mathrm{~g} / \mathrm{kg}$ for mouse and $1.2 \mathrm{~g} / \mathrm{kg}$ for rat) 
for adult animals, but caused severe diarrhea and appendicitis and finally death ( $80 \%$ mortality) in rats after $7-10$ days at higher doses $(2 \mathrm{~g} / \mathrm{kg})$.

AC compounds exhibited strong teratogenic effects on zebrafish embryos at low (micromolar) concentrations as can be seen on Fig. 6. The tail of the fish is bended and distorted (shortened and having an "S"-shaped break at the end) when compared to control animals. The same distortion effects can be seen for thalidomide treated animals. At the distortion site defect in muscle formation can be seen (in Fig. 6 arrows show distortion sites of the treated animals).

\section{Gene-expression changes of treated cancer cells}

To further investigate the mechanisms underlying growth inhibitory effects of amino-trifluoro-phthalimides on cancer cells, different cell lines (K562, HL60, U266, HT168, U87, HepG2 and MCF7) were treated with AC1041 at an $\mathrm{IC}_{50}$ concentration for $4 \mathrm{~h}$. Using treated $\mathrm{K} 562$ cells a gene array analysis was performed with DNAmicroarrays. Microarray data were deposited at GEO (Gene Expression Omnibus) database with an accession number GSE14945. AC-1041 activated expression of a set of genes involved in the ER stress (ATF3, DDIT3 (GADD153), HERPUD1, PP1R15A, DNAJB1, DNAJB4, DNAJB9, FOS, FOSB, JUN, NR4A1, NR4A2, RELB, TRIB3, $L C R F)$. Other set of induced genes are coding for tumor suppressor proteins (TP53, ING3, LATS2) or part of the JNK/p38 pathway (DUSP1, DUSP8, DUSP10). A specific marker gene of cell division, CCND1 coding for cyclin D1 was down-regulated. Significant repression of CCL2 (chemokine C-C motif ligand 2, or MCP-1), and induction of $S N X 16$ (sorting nexin 16) could be detected. To confirm the expression of these genes QRT-PCR was done (K562 column in Table 1). In order to assess the effects of AC-1041 on other cell lines (HL60, U266, HT168, U87, HepG2 and MCF7) the expression of these genes were also studied (Table 1). While almost in all cell

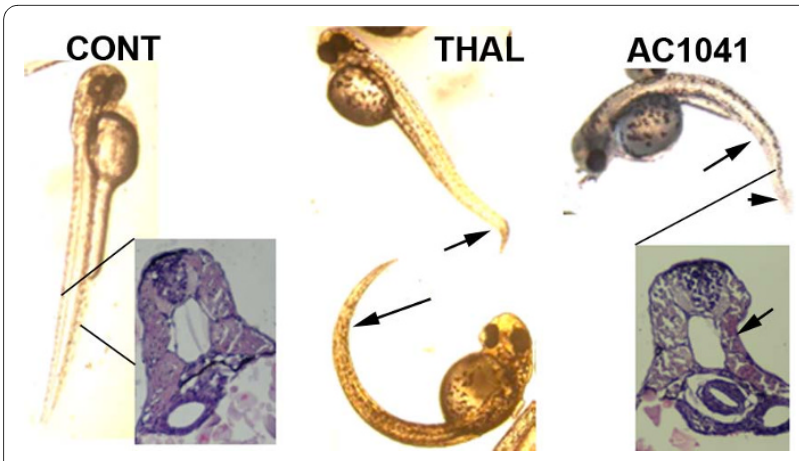

Figure 6 Teratogenic activity of AC-1041 on zebrafish embryos Control embryo (CONT), Thalidomide treated (5 $\mu \mathrm{M}$; THAL) and AC1041 treated (5 $\mu \mathrm{M}$; AC-1041) embryos (b), photo was taken at $3 \mathrm{dpf}$ (days post fertilization). Histological sections show differences in muscle structure after treatment. Arrows indicates malformations. lines the induction of ER stress-related genes could be observed, changes at the mRNA level of TP53, ING3, the DUSP family and SNX16 could be recorded only in the sensitive cells (leukemia and myeloma) and not in other cell lines.

\section{Discussion}

The potential to alter tumor-lipid homeostasis through nutritional intervention was established from observations that tumors derive their fatty acids from the de novo synthesis pathway that generates stearic and oleic acid [25]. When the synthesis is over-balanced or when fatty acid degradation by beta-oxidation is repressed due to hypoxic conditions, cells direct their excess fatty acids into intracellular lipid depots, into LDs. The lipid in these droplets undergoes turnover via hydrolysis and re-synthesis providing excellent target for affecting tumor cell survival. Moreover LDs have recently been suggested to represent target compartments for fatty acid scavenging to protect cells from lipoapoptosis [26]. We hypothesized that small molecules interacting with LDs cause imbalance in lipid homeostasis resulting in membrane disruption that can finally lead to apoptosis.

We synthesized novel thalidomide analogs (2,6-dialkylphenyl-4/5-amino-substituted-5,6,7-trifluorophthalimides) that possess bright blue fluorescence. They exerted potent anticancer activities in vitro in different cell lines: leukemia (K562, HL60), myeloma (U266), glioblastoma (U87), melanoma (HT168), breast cancer (MCF7) and hepatocellular carcinoma (HepG2). In human erythroleukemia cells (K562), which showed significant resistance against several thalidomide analogs [15], amino-trifluorophthalimides were effective below $10 \mu \mathrm{M}$ concentration. We showed that amino-trifluoro-phthalimides localize to LDs and at higher concentrations to ER. Moreover, oral administration of AC-202 resulted in staining LD of metastatic melanoma grown in the liver of xenograft mouse (Fig. 2g-i), suggesting not only good oral bioavailability but also accumulation of the drugs in LDs of pre-necrotic cancer tissues.

Based on our hypothesis regarding to ER membrane disturbance of the LD-binding compounds and previous findings on "redox-reactive" thalidomide analogs [15], we studied the effects of the amino-trifluoro-phthalimides on intracellular calcium release and ROS formation. In K562 cells they induced intracellular calcium ion release from the ER. They evoked a large initial peak in $\left[\mathrm{Ca}^{2+}\right]_{\mathrm{i}}$ followed by a sustained plateau or induced repetitive $\left[\mathrm{Ca}^{2+}\right]_{\mathrm{i}}$ transients (Fig. 4.). AC-177 and other analogs generated significant levels of ROS in HT168 (and K562, not shown) cells, while control compounds cc5013, thalidomide and CPS-49 showed only minimal elevation compared with that of untreated cells. ROS formation could 
Table 1: Expression changes in different cells after AC-1041 treatment.

\begin{tabular}{|c|c|c|c|c|c|c|c|c|c|}
\hline Code & Acc. No. & Gene product & K562 & HL60 & U266 & HT168 & U87 & HEPG2 & MCF7 \\
\hline $\mathrm{CCL} 2$ & NM_002982 & $\begin{array}{l}\text { Chemokine (C-C motif) } \\
\text { ligand } 2\end{array}$ & $\underline{0.31}$ & $\underline{0.35}$ & $\underline{0.37}$ & n.d. & 0.80 & $\underline{0.34}$ & $\underline{0.51}$ \\
\hline ATF3 & NM_004024 & $\begin{array}{l}\text { Activating transcription } \\
\text { factor } 3\end{array}$ & 10.21 & 2.75 & 8.17 & 18.29 & 4.10 & 0.66 & 4.32 \\
\hline DDIT3 & NM_004083 & $\begin{array}{l}\text { DNA-damage-inducible } \\
\text { transcript } 3\end{array}$ & 3.73 & 3.28 & 6.19 & 3.67 & 2.84 & 2.91 & 6.43 \\
\hline LCRF & NM_153607 & $\begin{array}{l}\text { Luman/CREB3 } \\
\text { rercruitment factor }\end{array}$ & 4.19 & 10.02 & 2.02 & 12.49 & 2.38 & 2.45 & n.d. \\
\hline DNAJB1 & NM_006145 & DnaJ (Hsp40) homolog B1 & 10.14 & 3.23 & 4.15 & 10.41 & 5.93 & 5.67 & 2.09 \\
\hline HERPUD1 & NM_014685 & $\begin{array}{l}\text { ER stress-inducible, } \\
\text { ubiquitin-like } 1\end{array}$ & 2.76 & 1.76 & 1.02 & 7.63 & 2.57 & 3.81 & 2.03 \\
\hline HSPH1 & NM_006644 & $\begin{array}{l}\text { Heat shock } 105 \mathrm{kDa} / \\
110 \mathrm{kDa} \text { protein } 1\end{array}$ & 3.64 & 2.69 & 1.70 & 3.26 & 1.88 & 2.27 & 0.89 \\
\hline TP53 & NM_000546 & Tumor protein p53 & 2.37 & 7.62 & 1.07 & 1.31 & 1.01 & 1.05 & 4.02 \\
\hline ING3 & NM_019071 & $\begin{array}{l}\text { Inhibitor of growth family, } \\
\text { member } 3\end{array}$ & 1.63 & 2.10 & 1.80 & 1.92 & 1.59 & 0.72 & 2.51 \\
\hline LATS2 & NM_014572 & $\begin{array}{l}\text { LATS, large tumor } \\
\text { suppressor, homolog } 2\end{array}$ & 2.62 & 1.73 & 1.20 & 3.57 & 2.11 & $\underline{0.24}$ & 0.65 \\
\hline CCND1 & NM_053056 & Cyclin D1 & $\underline{0.46}$ & 1.13 & 1.00 & 0.85 & 1.19 & 2.12 & 1.12 \\
\hline DUSP1 & NM_004417 & $\begin{array}{l}\text { Dual specificity } \\
\text { phosphatase } 1\end{array}$ & 3.77 & 1.30 & 5.29 & 0.94 & 1.66 & 0.94 & 1.62 \\
\hline DUSP8 & NM_004420 & $\begin{array}{l}\text { Dual specificity } \\
\text { phosphatase } 8\end{array}$ & 9.23 & 5.81 & 7.94 & 1.01 & 2.68 & 1.91 & 1.80 \\
\hline DUSP10 & NM_007207 & $\begin{array}{l}\text { Dual specificity } \\
\text { phosphatase } 10\end{array}$ & 2.86 & 2.22 & 2.05 & 0.81 & 1.30 & 1.21 & 3.35 \\
\hline SNX16 & NM_022133 & Sorting nexin 16 & 3.19 & 3.07 & 1.39 & 1.07 & 0.75 & 1.24 & 1.92 \\
\hline
\end{tabular}

Down-regulated gene expression values ( $<1.80$-fold) are indicated by bold, underlined numbers, induced expression values ( $>1.80$-fold) by bold and italics.

be substantially decreased by the cell-permeable calcium chelator, BAPTA-AM, which suggests correlation between the elevation of intracellular calcium ion concentration and ROS production induced by the analogs. Different antioxidants partially diminished ROS production, but significant reduction could be achieved only with NAC and tiron. Interestingly, vitamin C elevated the AC-177 induced ROS formation. The same effect could be observed when DHA or EPA was added in combination with AC-177 (Fig. 5B). This effect could be explained by affecting the membrane structure of the ER by polyunsaturated fatty acids and sensitization of cells against ROS forming agents. However, oleic acid does not display such effect neither alone nor in combination with AC-177.

A species-specific conversion to free radical intermediates in embryonic tissue was suspected to be the main reason for thalidomide teratogenicity [27]. Therefore, we studied the teratogenic effects of the LD-binding thalidomide analogs and thalidomide as a control on zebrafish embryos. AC-177, AC-202 and AC-1041 caused severe morphological changes in the fish like distortion of mus- cle development and curves in their tails at micromolar concentrations (Fig. 6). The same pathological phenomena could be detected in the case of thalidomide and other thalidomide analogs. It is interesting that zebrafish is sensitive to thalidomide, whereas mice and rats are not. Similar sensitivity for aflatoxins and dimethylnitrosamine could be found in rainbow trout to generate primary liver carcinoma $[28,29]$. Besides the teratogenicity of the analogs, in initial animal studies, high levels of AC-202 and AC-1041 were well tolerated in adults, and they showed no toxicity even at $1 \mathrm{~g} / \mathrm{kg}$ dose. Therefore, the LD-binding thalidomide analogs are ideal candidates for further in vivo studies and possibly for entering into clinical trials against cancer.

Thalidomide and its analogs have been discovered to have various biological activities, such as anti-inflammatory, anti-angiogenic, cyclooxygenase (COX)-inhibitory and microtubule-perturbing activities [24,30-32]. However, there are only limited numbers of studies revealing the mechanisms of action of different analogs by using gene expression fingerprinting or clustering of different 
biological patterns. In the present study we applied DNAmicroarrays and QRT-PCR to identify early genes affected by the analogs. AC-1041 induced the expression of 251 genes and repressed 37 genes (data for all of the 14,833 genes examined can be seen at GEO database with an accession number of GSE14945) in K562 cells after $4 \mathrm{~h}$ treatment. Microarray results showed that a large number of genes associated with the ER stress response are rapidly induced by AC-1041. This suggests that AC-1041induced apoptosis is coupled to the ER stress response. During this response, several pro-survival and pro-apoptotic signals are activated and, depending on the extent of the ER stress, cells survive or when functions of the ER are severely impaired, they undergo apoptosis [33,34]. One of the most universal components of the ER stressmediated apoptosis pathway is $C / E B P$ homologous protein $(C H O P)$, also known as GADD153 or DDIT3 [35], which is markedly induced by AC-1041. Other induced genes code for proteins that are part of the JNK/p38 pathway (DUSP1, DUSP8, DUSP10) and have roles in regulation of cellular stress responses [36]. Tumor suppressor genes (TP53, ING3, LATS2) were also induced, while a specific marker gene of cell division, CCND1 coding for cyclin D1 was down-regulated. Interestingly, expression of other genes that could explain multiple action of thalidomide analogs in vivo were also changed. CCL2 was repressed and $S N X 16$ was induced by more than 3 -fold as assessed by QRT-PCR. CCL2 is a member of the cytokine/chemokine superfamily and is known to promote the migration of monocytes and macrophages to sites of inflammation and having roles in the tumorigenesis and metastasis of several solid tumors [37,38]. It was also demonstrated that CCL2 acts as a direct mediator of angiogenesis [39]. SNX16 directs the sorting of EGFR from early endosomes to lysosomes and thus has critical role in the termination of EGF-induced cell signaling $[40,41]$.

To further investigate the mechanisms underlying growth inhibitory effects of amino-trifluoro-phthalimides different cell lines (K562, HL60, U266, HT168, U87, HepG2 and MCF7) were treated with $\mathrm{AC}-1041$ at an $\mathrm{IC}_{50}$ concentration and gene expression changes were followed for 15 key genes (Table 1). The induction of ER stress-related genes and repression of CCL2 could be observed in all cell lines, suggesting common mechanism of action. Differences could be seen in case of TP53, ING3, DUSP family and cyclin D1, which correlated with the chemo-sensitivity of the cells.

Considering the positive effects of AC-1041 on altering CCL2 and SNX16 expression, it is likely that these effects (angiogenesis and tumorigenesis inhibition by CCL2 repression, and epidermal growth factor receptor downregulation by $S N X 16$ induction) in addition to induction of ER stress pathways are important and specific for the biological effects of amino-trifluoro-phthalimides on cancer cells.

\section{Conclusions}

Here we report, that interference with lipid homeostasis and ER membrane integrity of LD-binding thalidomide analogs and the subsequently induced ER stress are crucial steps in the cytotoxic action of these molecules. Additionally to this common pathway that are affected by "redox-reactive" thalidomide analogs, repression of CCL2 and induction of $S N X 16$ could explain the multiple therapeutic actions of IMiDs. Our results might open novel therapeutic strategies for anti-cancer drug discovery and therapy by using LD-binding molecules and also emphasize the importance of anti-neoplastic agents that affect vesicle transport and the homeostasis of the ER.

\section{Abbreviations}

TAG: triacylglycerol; LD: lipid droplet; ER: endoplasmic reticulum; EPA: eicosapentaenoic acid (20:5: n-3); QRT-PCR: quantitative real-time PCR; MTS: 3-(4,5dimethylthiazol-2-yl)-5-(3-carboxymethoxyphenyl)-2-(4-sulfophenyl)-2H-tetrazolium; ROS: reactive oxygen species; GSH: gluthatione; NAC: N-acetyl cysteine; BSO: buthylsulfoxide;

\section{Competing interests}

PGL, CEO of Avidin Ltd., has interests in the commercialization of novel thalidomide analogs studied in the current article. Avidin Ltd. also has patent in the area of thalidomide analogs.

\section{Authors' contributions}

Fluorescent thalidomide analogs were synthesized by IK, MG, RM. Confocal laser scanning microscopy was performed by FA, LZF. Affinity chromatography, polyacrylamide gel-electrophoresis and mass spectrometry involved LZF, GF, EM. Cytotoxicity assays involved BO, LZF. Intracellular $\mathrm{Ca}^{2+}$ measurements were performed by $\mathrm{PH}, \mathrm{KF}, \mathrm{GF}$. GF also participated in ROS generation which was determined by flow cytometry. Gene expression analysis involved LZF, LGP. IM and FB was performed teratogenic analysis. Data analysis, drafting of the manuscript was performed by LGP, KK, CV and ER. All authors read and approved the final version.

\section{Acknowledgements}

This work was partly supported by grants from the Oszkár Asbóth "XTTPSRT1", Ányos Jedlik "AVINOMID" and National Technology Program "GLINOLID" (National Research and Technology Office, Hungary). CV and KK were supported by the János Bolyai Research Scholarship of the Hungarian Academy of Sciences.

\section{Author Details}

1 Avidin Biotechnology, Közép fasor 52., Szeged, H-6726, Hungary, ${ }^{2}$ Avicor Ltd., Közép fasor 52., Szeged, H-6726, Hungary, 3Laboratory of Functional Genomics, Institute of Genetics, Biological Research Center, Hungarian Academy of Sciences, Temesvári krt. 62., Szeged, H-6726, Hungary, ${ }^{4}$ Institute of Biochemistry, Biological Research Center, Hungarian Academy of Sciences, Temesvári krt. 62., Szeged, H-6726, Hungary, ${ }^{5}$ Cellular Imaging Laboratory, Biological Research Center, Hungarian Academy of Sciences, Temesvári krt. 62. Szeged, H-6726, Hungary, ${ }^{6}$ National Institute of Oncology, Ráth György u. 7-9., Budapest, H-1011, Hungary, 7Biotecont Ltd., 1/1. Finn u., Pécs, H-7630, Hungary , 8First Department of Medicine, University of Szeged, Korányi fasor 8-10., Szeged, H-6720, Hungary and ${ }^{9}$ Faculty of Veterinary Science, Szent István University, István u. 2. Budapest, H-1078, Hungary

Received: 27 April 2010 Accepted: 2 June 2010 Published: 2 June 2010 


\section{References}

1. Londos C, Brasaemle DL, Schultz CJ, Segrest JP, Kimmel AR: Perilipins, ADRP, and other proteins that associate with intracellular neutral lipid droplets in animal cells. Semin Cell Dev Biol 1999, 10:51-58.

2. Brown DA: Lipid droplets: proteins floating on a pool of fat. Curr Biol 2001, 11:446-449.

3. Frolov A, Petrescu A, Atshaves BP, So PT, Gratton E, Serrero G, Schroeder F: High density lipoprotein-mediated cholesterol uptake and targeting to lipid droplets in intact L-cell fibroblasts. A single- and multiphoton fluorescence approach. J Biol Chem 2000, 275:12769-12780.

4. Prattes S, Horl G, Hammer A, Blaschitz A, Graier WF, Sattler W, Zechner R, Steyrer E: Intracellular distribution and mobilization of unesterified cholesterol in adipocytes: triglyceride droplets are surrounded by cholesterol-rich ER-like surface layer structures. J Cell Sci 2000 113:2977-2989.

5. Murphy DJ, Vance J: Mechanisms of lipid-body formation. Trends Biochem Sci 1999, 24:109-115.

6. Liu P, Bartz R, Zehmer JK, Ying YS, Zhu M, Serrero G, Anderson RG: Rabregulated interaction of early endosomes with lipid droplets. Biochim Biophys Acta 2007, 1773:784-793.

7. Bozza PT, Melo RC, Bandeira-Melo C: Leukocyte lipid bodies regulation and function: contribution to allergy and host defense. Pharmacol Ther 2007, 113:30-49.

8. Bostrom P, Magnusson B, Svensson PA, Wiklund O, Boren J, Carlsson LM, Stahlman M, Olofsson SO, Hulten LM: Hypoxia converts human macrophages into triglyceride-loaded foam cells. Arterioscler Thromb Vasc Biol 2006, 8:1871-1876.

9. Quintero M, Cabanas ME, Arus C: A possible cellular explanation for the NMR-visible mobile lipid (ML) changes in cultured $\mathrm{C} 6$ glioma cells with growth. Biochim Biophys Acta 2007, 1771:31-44.

10. Bilheimer DW, Buja LM, Parkey RW, Bonte FJ, Willerson JT: Fatty acid accumulation and abnormal lipid deposition in peripheral and border zones of experimental myocardial infarcts. J Nucl Med 1978, 19:276-283.

11. Straeter-Knowlen IM, Evanochko WT, den Hollander JA, Wolkowicz PE, Balschi JA, Caulfiled JB, Ku DD, Pohost GM: 1 H NMR spectroscopic imaging of myocardial triglycerides in excised dog hearts subjected to 24 hours of coronary occlusion. Circulation 1996, 93:1464-1470.

12. Borradaile NM, Han X, Harp JD, Gale SE, Ory DS, Schaffer JE: Disruption of endoplasmic reticulum structure and integrity in lipotoxic cell death. J Lipid Res 2006, 12:2726-2737.

13. Bartlett JB, Dredge K, Dalgleish AG: The evolution of thalidomide and its IMiD derivatives as anticancer agents. Nat Rev Cancer 2004, 4:314-322.

14. Ng SS, Gütschow M, Weiss M, Hauschildt S, Teubert U, Hecker TK, Luzzio FA, Kruger EA, Eger K, Figg WD: Antiangiogenic activity of N-substituted and tetrafluorinated thalidomide analogues. Cancer Res 2003, 63:3189-3194

15. Ge Y, Montano I, Rustici G, Freebern WJ, Haggerty CM, Cui W, PoncianoJackson D, Chandramouli GV, Gardner ER, Figg WD, Abu-Asab M, Tsokos $M$, et al: Selective leukemic-cell killing by a novel functional class of thalidomide analogs. Blood 2006, 108:4126-4135.

16. Matthews SJ, McCoy C: Thalidomide: a review of approved and investigational uses. Clin Ther 2003, 2:342-395.

17. Calabrese L, Fleischer AB: Thalidomide: current and potential clinical applications. Am J Med 2000, 108:487-495.

18. Capitosti SM, Hansen TP, Brown ML: Thalidomide analogues demonstrate dual inhibition of both angiogenesis and prostate cancer. Bioorg Med Chem 2004, 12:327-336.

19. Lima LM, Castro P, Machado AL, Fraga CA, Lugnier C, d Moraes VL, Barreiro EJ: Synthesis and anti-inflammatory activity of phthalimide derivatives, designed as new thalidomide analogues. Bioorg Med Chem 2002, 10:3067-3073

20. Man HW, Corral LG, Stirling DI, Muller GW: Alpha-fluoro-substituted thalidomide analogues. Bioorg Med Chem Lett 2003, 13:3415-3417.

21. Miyachi H, Ogasawara A, Azuma A, Hashimoto Y: Tumor necrosis factoralpha production-inhibiting activity of phthalimide analogues on human leukemia THP-1 cells and a structure-activity relationship study. Bioorg Med Chem 1997, 5:2095-2102.

22. Yang L, Ho NY, Alshut R, Legradi J, Weiss C, Reischl M, Mikut R, Liebel U, Müller F, Strähle U: Zebrafish embryos as models for embryotoxic and teratological effects of chemicals. Reprod Toxicol 2009, 28:245-53.

23. Puskas LG, Bereczki E, Santha M, Vigh L, Csanadi G, Spener F, Ferdinandy P, Onochy A, Kitajka K: Cholesterol and cholesterol plus DHA diet-induced gene expression and fatty acid changes in mouse eye and brain. Biochimie 2004, 86:817-824.

24. Li PK, Pandit B, Sackett DL, Hu Z, Zink J, Freeman D, Robey RW, Werbovetz K, Lewis A, Li C: A thalidomide analogue with in vitro antiproliferative, antimitotic, and microtubule-stabilizing activities. Mol Cancer Ther 2006, 5:450-456.

25. Spector AA, Imig B: Effect of free fatty acid concentration on the transport and utilization of other albumin-bound compounds: hydroxyphenylazobenzoic acid. J Biol Chem 1967, 242:3057-3062.

26. Öst A, Ortegren U, Gustavsson J, Nystrom FH, Strålfors P: Triacylglycerol is synthesized in a specific subclass of caveolae in primary adipocytes. $J$ Biol Chem 2005, 280:5-8

27. Parman T, Wiley MJ, Wells PG: Free radical-mediated oxidative DNA damage in the mechanism of thalidomide teratogenicity. Nat Med 1999, 5:582-585.

28. Halver JE, Johnson CL, Ashley LM: Dietary carcinogens induce fish hepatoma. Fed Proc 1962, 21:390

29. Ashley LM, Halver JE: Dimethylnitrosamine-Induced Hepatic Cell Carcinoma in Rainbow Trout. J Nat Cancer Inst 1968, 41:531-552.

30. D'Amato RJ, Loughnan MS, Flynn E, Folkman J: Thalidomide is an inhibitor of angiogenesis. Proc Natl Acad Sci USA 1994, 91:4082-4085.

31. Noguchi T, Shimazawa R, Nagasawa K, Hashimoto Y: Thalidomide and its analogues as cyclooxygenase inhibitors. Bioorg Med Chem Lett 2002, 12:1043-1046.

32. Yanagawa $T$, Noguchi $T$, Miyachi $H$, Kobayashi $H$, Hashimoto $Y$ : Tubulin polymerization inhibitors with a fluorinated phthalimide skeleton derived from thalidomide. Bioorg Med Chem Lett 2006, 16:4748-4751

33. Wu J, Kaufman RJ: From acute ER stress to physiological roles of the unfolded protein response. Cell Death Differ 2006, 13:374-384

34. Ferri KF, Kroemer G: Organelle-specific initiation of cell death pathways. Nat Cell Biol 2001, 3:E255-E263.

35. Oyadomari S, Mori M: Roles of CHOP/GADD153 in endoplasmic reticulum stress. Cell Death Differ 2004, 11:381-389.

36. Dickinson RJ, Keyse SM: Diverse physiological functions for dualspecificity MAP kinase phosphatases. J Cell Sci 2006, 119:4607-4615.

37. Loberg RD, Ying C, Craig M, Yan L, Snyder LA, Pienta KJ: CCL2 as an important mediator of prostate cancer growth in vivo through the regulation of macrophage infiltration. Neoplasia 2007, 9:556-562.

38. Ohta M, Kitadai Y, Tanaka S, Yoshihara M, Yasui W, Mukaida N, Haruma K, Chayama K: Monocyte chemoattractant protein-1 expression correlates with macrophage infiltration and tumor vascularity in human esophageal squamous cell arcinomas. Int J Cancer 2002, 102:220-224.

39. Salcedo R, Ponce ML, Young HA, Wasserman K, Ward JM, Kleinman HK, Oppenheim JJ, Murphy WJ: Human endothelial cells express CCR2 and respond to MCP-1: direct role of MCP-1 in angiogenesis and tumor progression. Blood 2000, 96:34-40.

40. Choi JH, Hong WP, Kim MJ, Kim JH, Ryu SH, Suh PG: Sorting nexin 16 regulates EGF receptor trafficking by phosphatidylinositol-3phosphate interaction with the Phox domain. J Cell Sci 2004, 117:4209-4218

41. Gullapalli A, Garrett TA, Paing MM, Griffin CT, Yang Y, Trejo J: A role for sorting nexin 2 in epidermal growth factor receptor down-regulation: evidence for distinct functions of sorting nexin 1 and 2 in protein trafficking. Mol Biol Cell 2004, 15:2143-55.

doi: 10.1186/1476-511X-9-56

Cite this article as: Puskás et al., Polyunsaturated fatty acids synergize with lipid droplet binding thalidomide analogs to induce oxidative stress in cancer cells Lipids in Health and Disease 2010, 9:56 